\title{
OPINIÕES DE MÃES E PROFISSIONAIS SOBRE A SEXUALIDADE DE PESSOAS COM DEFICIÊNCIA INTELECTUAL
}

\author{
Josiane Peres Gonçalves ' \\ Maria Madalena Freitas Barbosa²
}

\section{RESUMO}

O objetivo deste estudo é investigar sobre a sexualidade de pessoas com deficiência intelectual, segundo a perspectiva de profissionais e familiares que convivem com essa realidade. A pesquisa de natureza qualitativa foi realizada com três profissionais e três responsáveis por pessoas adultas com deficiência intelectual. Os resultados indicam que existem alguns mitos em relação ao assunto que não se confirmam na prática, havendo a necessidade de superação desses mitos. Concluise que a sexualidade é a mais normal das características humanas sentidas por todos e, sendo assim, todos têm o direito de usufruí-la, inclusive as pessoas que têm deficiência intelectual.

Palavras-chave: Sexualidade. Deficiência Intelectual. Educação sexual.

\section{MOTHERS AND PROFESSIONALS' OPINIONS ON THE SEXUALITY OF PEOPLE WITH INTELLECTUAL DISABILITIES}

\begin{abstract}
The objective of this study is to investigate the sexuality of people with intellectual disabilities, from the perspective of professional and family who live with this reality. The qualitative research was conducted with three professional and three account for adults with intellectual disabilities. The results indicate that there are some myths on the subject that are not confirmed in practice, there is the need to overcome these myths. It concludes that sexuality is the most normal human characteristics felt by all and, therefore, everyone has the right to enjoy it, including people who have intellectual disabilities.
\end{abstract}

Keywords: Sexuality. Intellectual Disabilities. Sex Education.

1 Doutora em Educação pela Pontifícia Universidade Católica do Rio Grande do Sul (PUCRS). Professora Permanente do Programa de Pós-graduação em Educação da Universidade Federal de Mato Grosso do Sul Campus do Pantanal (CPAN/UFMS) e do Programa de Pós-Graduação em Educação da Faculdade de Educação (FAED/UFMS). Líder do Grupo de Estudo e Pesquisa em Desenvolvimento, Gênero e Educação (GEPDGE). Orcid iD: https://orcid.org/0000-0002-7005-849X. E-mails: josiane.peres@ufms.br; josianeperes7@hotmail.com

2 Graduada em Pedagogia pela Universidade Federal de Mato Grosso do Sul, Câmpus de Naviraí (UFMS/CPNV). Professora de Educação Infantil da Rede Municipal de Ensino de Naviraí. Orcid iD: https://orcid.org/0000-0003-1849-3379. E-mail: lena_fesb@hotmail.com 


\section{OPINIONES DE MADRES Y PROFESIONALES SOBRE LA SEXUALIDAD DE LAS PERSONAS CON DISCAPACIDAD INTELLECTUAL}

\section{RESUMEN}

El objetivo de este estudio es investigar sobre la sexualidad de personas con discapacidad intelectual, según la perspectiva de profesionales y familiares que conviven con esa realidad. La investigación de naturaleza cualitativa fue realizada con tres profesionales y tres responsables por personas adultas con discapacidad intelectual. Los resultados indican que existen algunos mitos en relación al asunto que no se confirman en la práctica, habiendo la necesidad de superación de esos mitos. Se concluye que la sexualidad es la más normal de las características humanas sentidas por todos y, siendo así, todos tienen el derecho de usufructuarla, incluso las personas que tienen discapacidad intelectual.

Palabras clave: La sexualidade. Deficiencia Intelectual. Educación Sexual.

\section{INTRODUÇÃO}

A questão da sexualidade ainda é um tabu para muitos e em se tratando de pessoas com deficiência o tema toma outra dimensão, ficando restrito aos profissionais da área e a família. Mas o silêncio foi quebrado com a espontaneidade das pessoas com deficiência frente às transformações oferecidas pela própria sociedade, manifestando seus sentimentos e desejos outrora privados.

Nesse processo de rompimento de silêncio é que surge o interesse pelo tema, despertando o interesse em melhor compreender essa questão, mediante a realização de uma pesquisa bibliográfica e de campo. Assim, o presente estudo tem por objetivo investigar sobre a sexualidade de pessoas com deficiência intelectual, segundo a perspectiva de profissionais e familiares que convivem com essa realidade. Entende-se que além de ser um desafio para pais e educadores, a proposta configura-se como ousada, oportuna e necessária, por possibilitar uma reflexão e aprofundamento da questão sexualidade da pessoa com deficiência intelectual.

Para atender a esse objetivo, foi realizada pesquisa bibliográfica fundamentada em autores como Ribeiro (2010); Gaglioto, Faust e Santos (2009), Gaglioto (2009), Fávero (2013), Musskopf (2014), Pinheiro (2004), Souza (2014), Redece (2014), Gonçalves, Bezerra e Novais (2018) e Dreyer, Mateus e 
Gonçalves (2018). Entre os autores pesquisados, o destaque é para Ana Claudia Maia, grande pesquisadora, com vários artigos e livros relacionados ao tema, dentre eles Maia (2001) Reflexões Sobre a Educação da Pessoa com Deficiência; Além de documentos como: OS PCNS (Parâmetros curriculares nacionais), ECA (Estatuto da criança e do adolescente).

Também foi realizada uma pesquisa de campo com profissionais que atuam na instituição APAE de Navirai, sendo uma psicóloga, uma gestora e uma professora, além de três responsáveis por alunos que estudam na instituição: duas mães e uma irmã cuidadora. Os resultados dos estudos bibliográficos e pesquisa de campo são apresentados na sequência.

\section{SEXUALIDADE DE PESSOAS COM DEFICIÊNCIA INTELECTUAL}

O foco da temática a ser abordada é a sexualidade de pessoas com deficiência intelectual e como pais e profissionais podem garantir o seu usufruto. Segundo Maia e Ribeiro (2010), o termo sexualidade foi usado no século XIX, em estudos sobre os saberes das práticas sexuais construídas ao longo dos tempos.

Na cultura vigente, a questão da sexualidade ainda está envolta de preconceitos e discriminação e, em se tratando dos deficientes intelectuais o tema toma outra dimensão. Este preconceito existente impede que a pessoa com deficiência tenha acesso ao conhecimento necessário de sua sexualidade, logo são impedidos de compreender como se dá todo esse processo.

A falta de orientação os coíbe de entender e desenvolver seus sentimentos e desejos pertinentes em todos os seres humanos e muitas vezes são vistos como um ser assexuado, sem o direito de viver plenamente a sua sexualidade e seu afeto, sendo sua sexualidade carregada de conotações negativas e preconceituosas. No meio social, constantemente, pessoas se deparam com situações que levam ao constrangimento de indivíduos com deficiências (MAIA; RIBEIRO, 2010).

Esses indivíduos por muito tempo foram excluídos da sociedade, por serem considerados fora dos padrões normais, logo, não poderiam exercer 
os mesmos direitos que os ditos normais. Eram taxados como estranhos e subumanos a enviados de Deus. O assunto deficiente intelectual é algo que costuma ser de interesse apenas da família, professores e especialistas da área, e quando surge em conversas cotidianas, somente são destacados aspectos negativos, sentido apenas pelos membros que lidam com a situação.

Esse desinteresse por esse grupo da sociedade contribui para 0 isolamento e ausência de conhecimento com os aspectos que envolvem a sexualidade, conforme revelado por Pinheiro (2004, p. 204) que aborda sobre "[...] a não-existência de instrumentos brasileiros e nem de instrumentos estrangeiros adaptados para a nossa realidade com o objetivo de avaliar a sexualidade no portador de deficiência mental".

Atualmente o silêncio foi quebrado parcialmente, diante da evolução que vem ocorrendo na vida desses indivíduos, influenciados pela escola, TV, internet, família, sendo necessário que se faça estudo sobre o assunto, para que a sociedade, escola e a família saibam como tratá-los sem exclusão, respeitando direitos e deveres.

Logo, independente se a pessoa tenha ou não deficiência, é possível afirmar que a sexualidade é a mais normal das características humanas sentida por todos. Reconhecendo esta peculiaridade dos seres humanos, de ter direito a relação afetiva sexual, a abordagem analisará a conceituação de sexualidade e também se faz necessário ver no decorrer da história como era considerada essa temática no passado e nos nossos dias, para melhor entendê-la.

\section{CONCEITOS DE SEXUALIDADE}

A sexualidade embora tenha sua existência incontestada, é algo incorpóreo e imaterial. Souza (2008) apresenta o conceito de sexualidade, fornecendo um traçado do que as pessoas buscam para obter ou expressar prazer:

Considera-se sexualidade as diversas formas, jeitos, maneiras que as pessoas buscam para obter ou expressar prazer. É basicamente a busca do prazer humano em suas diversas formas. A idéia de prazer 
irá variar de pessoa para pessoa, levando em conta a realidade de cada indivíduo. Quando uma pessoa está sentindo prazer, ela está vivenciando a sua sexualidade. A busca do prazer se dá de várias formas, em variadas circunstâncias (SOUZA, 2008, p. 08-09).

As manifestações sexuais são aceitas por toda a população, a busca pelo prazer varia de pessoa para pessoa, respeitando as especificidades de cada um. Para Pinheiro (2004, p. 200), "[...] é um atributo de todo ser humano, não é algo que a pessoa tenha, é algo que se é que o ser humano constrói ao longo de sua vida envolvendo uma série de manifestações". Baseando-se nesse pressuposto, constatamos que encontrar uma definição padrão específica para sexualidade é muito difícil, praticamente tarefa impossível de acontecer.

A sexualidade, de acordo com os Parâmetros Curriculares Nacionais (PCNs 1990), é vista sob ângulos diferentes considerando questões territoriais, culturais, dentre crenças e hábitos. O sexo, em contrapartida, é o material, o que se percebe, o que identifica uma característica física de uma pessoa, é apenas um dos objetivos da sexualidade e com ela não se confunde, embora dela faça parte. A palavra sexo, segundo o Mini dicionário Escolar Língua portuguesa (2001, p. 492), é: com formação característica que distingue o macho da fêmea nos animais e vegetal. Os órgãos sexuais externos. Ao falar sobre sexo, Musskopf (2008, p. 58) constata que:

[...] refere-se ao dado físico-biológico, marcado pela presença de aparelho genital e outras características fisiológicas que diferenciam os seres humanos como machos e fêmeas; além destas, a partir de pesquisas recentes, também o código genético precisa ser considerado na constituição do sexo, o que complexifica as definições neste âmbito, cujo principal exemplo são as inúmeras formas de intersexualidade.

O código genético determina todas as características físicas que um indivíduo vai herdar, considerando a constituição das características sexuais. Uma das características marcantes que define o sexo é o aparelho sexual, denominado vagina e clitóris no sexo feminino, pênis no sexo masculino. 
Segundo Fávero (2013), nem sempre a sexualidade necessita dessa exacerbada relação com o sexo:

Sexualidade é uma característica geral experimentada por todo o ser humano e não necessita de relação exacerbada com o sexo, uma vez que se define pela busca de prazeres, sendo estes não apenas os explicitamente sexuais. Pode-se entender como constituinte de sexualidade, a necessidade de admiração e gosto pelo próprio corpo, por exemplo, o que não necessariamente signifique uma relação narcísica de amor incondicional ao ego (FÁVERO, 2013, p. 1).

Entretanto, sexualidade não é a busca aguçada pelo sexo, mas pela admiração de si mesmo, como ser igual a qualquer outro, porém com limitações que precisam ser trabalhadas formas que estimulem a sexualidade experimentada por todo ser humano. Porém, existem muitas definições para o termo sexualidade, que denota especulações nas bibliografias, dentre as várias definições para a sexualidade a que melhor traduz o objetivo do presente trabalho:

Sexualidade é essa necessidade de receber e expressar afeto e contato, que todas as pessoas têm e que traz sensações prazerosas e gostosas para cada um. Assim, sexualidade não é apenas sexo, a vida. É o toque, o abraço, o gesto, a palavra que transmite prazer entre pessoas e que temos desde antes de nascer, na barriga da mãe, quando bebês e durante toda a vida. Conforme vamos crescendo, descobrimos também o prazer provocado pelo contato sexual, através do estímulo que fazemos em nós mesmos ou com outras pessoas. Essa forma de exprimir a sexualidade vai se juntar às outras maneiras de contato que já vínhamos vivendo desde bebês, gerando a sexualidade adulta (REDECE, 2014, p. 01).

Sexualidade não é apenas sexo, mas muito mais do que ele. Ela engloba toda uma série de experiências de bem-estar geradas por confortos físicos e emocionais provocadas pelo autocontato, carinhos, relacionamentos com outras pessoas, toques físicos e, até o sexo propriamente dito. Para Dreyer, Mateus e Gonçalves (2018, p. 261), "A sexualidade é manifestada de diferentes formas a cada etapa do desenvolvimento humano, sendo construída ao longo da vida. Encontra-se necessariamente marcada pela cultura, história, ciência, bem como pelos afetos e sentimentos". 
Ao refletir sobre a diferença entre sexo e sexualidade, Gagliotto, Faust e Santos (2012) enfatizam que a sexualidade pode ser entendida como uma orientação ética, com um desenvolvimento estético, com compromisso participativo e comunitário, sugerindo diálogos francos, adequando materiais didáticos que retratam o corpo de maneira adequada, com ética, coerência e serenidade. Gaglioto, Faust e Santos (2012, p. 05) sinalizam que "[...] o sexo é marca biológica e a sexualidade é marca humana, um conceito cultural constituído pela qualidade, pela significação do sexo".

A sexualidade é um bem incorpóreo, tendo uma elaboração científica e humanística, levando em conta o histórico psíquico do indivíduo, sobrepujando o senso comum de que sexualidade está ligada apenas aos órgãos genitais. Neste viés, Gaglioto (2009) comenta que:

É importante observarmos que a ciência médica, ao estabelecer a correlação entre sexualidade e reprodução, contribuiu fortemente para o distanciamento entre a sexualidade e a subjetividade. E é por isso que, ainda hoje, em pleno século XXI, no senso comum, é corrente pensar a sexualidade associada aos órgãos genitais, ao coito e às informações biológicas do nosso corpo, desvinculadas do desejo, do amor e do prazer (GAGLIOTO, 2009, p. 36).

Ao analisar a citação do autor, sobre associar sexualidade aos órgãos genitais, em pleno século XXI as pessoas ainda vêem a sexualidade ligada aos órgãos pênis e vagina, ou a reprodução humana. Agora é o momento de explicitar mais ainda a ideia de que a sexualidade é algo inerente à vida de todos, que inclui crianças, jovens, adultos e idosos, sejam pessoas com algum tipo de deficiência, ou não.

A ciência natural vê a questão da sexualidade apena para fins reprodutivos. Segundo Gagliotto (2009), a sexualidade da criança e do idoso não existe pelo fato desses dois grupos não estarem inseridos no grupo dos reprodutores, faz essa negação por ligar a sexualidade com o trabalho do organismo reprodutor, vinculando o extinto sexual como algo natural, isolado e reproduzido de maneira hereditária.

Essa questão torna-se mais dramática quando for relacionado com pessoas que possuem algum tipo de deficiência, o problema não está na 
deficiência e suas limitações, mas no conjunto de desinformações, preconceitos, tabus sociais e nos próprios limites que ainda há na área sexual. Estudos e pesquisas é que ajudarão na desmistificação e quebra dos tabus ainda existentes.

\section{MITOS E CRENÇAS SOBRE A SEXUALIDADE DAS PESSOAS COM DEFICIÊNCIA INTELECTUAL}

Ao estudar sobre a questão da sexualidade das pessoas com deficiência intelectual, Maia e Ribeiro (2010) apresentam diversos mitos e crenças errôneas existentes na sociedade sobre este assunto. Os principais mitos identificados pelas autoras são parafraseados e interpretados na sequência:

Mito 1 - Pessoas com deficiência são assexuadas: não têm sentimentos, pensamentos e necessidades sexuais, porque são consideradas como dependentes e incapazes de exercer uma vida sexual adulta. Segundo Maia e Ribeiro (2010), esse pensamento demonstra o preconceito que permeia na sociedade, falta nas pessoas conhecimento das relações humanas, um olhar positivo na questão das deficiências. A educação sexual visa à formação da pessoa, com capacidade de crescer interiormente, viver e escolher sua sexualidade, como cidadão, assim como o faz a educação formal.

Mito 2 - Pessoas com deficiência são hiperssexuadas: seus desejos são incontroláveis e exacerbados. $O$ interesse pelo sexo por parte de pessoas com deficiência intelectual é o mesmo sentido por pessoas ditas como "normais", o que difere é que muitas vezes demonstram comportamentos sexuais publicamente, levando pessoas preconceituosas a formar ideias negativas. Para Pinheiro (2004), existe uma visão deturpada a respeito de desejos incontroláveis das pessoas com deficiência intelectual, não existe uma característica específica da sexualidade desses indivíduos, independente de deficiências, seus desejos sexuais são idênticos dos ditos "normais". Quando a pessoa com algum tipo de deficiência apresenta comportamento sexual fora dos padrões de normalidade, não é problema da deficiência, mas da forma como ele vem sendo tratado, e não pelo 
comprometimento intelectual. Outro aspecto em relação à fixação do sexo por parte da pessoa com deficiência está no fato de eles terem pouca atividade social, nas quais se pode adquirir prazer, mas isso não acontece só com eles, adolescentes não comprometidos neurologicamente também podem apresentar distúrbios sexuais ao vivenciar algum tipo de conflito, para sinalizar as dificuldades que estão sendo vivenciadas em outras áreas (MAIA; RIBEIRO; 2010).

Mito 3 - Pessoas com deficiência são pouco atraentes, indesejáveis e incapazes para manter um relacionamento amoroso e sexual. Ao analisar esse mito, estudos esclarecem que os padrões impostos pela mídia de conceito para um relacionamento aceitável têm a ver com corpo jovem, esbelto, perfeito, padrão esse que foge da realidade de toda a sociedade e serve de constrangimento. Para Maia e Ribeiro (2010), todas as pessoas têm dificuldades em seus relacionamentos amorosos. A deficiência pode apresentar algum tipo de dificuldade, mas não impede a pessoa de amar e ser amada. Assim, como todos os outros seres humanos, pessoas com deficiência intelectual, são capazes de manter relacionamentos amorosos, além disso, é de vital importância para suas vidas, como é para qualquer pessoa. Amar e ser amado são direito de todos independentes do nível intelectual de cada um (MAIA; RIBEIRO; 2010).

Mito 4 - Pessoas com deficiência não conseguem usufruir o sexo normal e têm disfunções sexuais relacionadas ao desejo, à excitação e ao orgasmo. Maia e Ribeiro (2010) afirmam que a maioria dos autores atualmente concorda que a sexualidade da pessoa com deficiência intelectual, tirando os casos considerados neurologicamente prejudicados, não é qualitativamente diferente dos demais, têm necessidades experienciais normais e emoções humanas normais, sabem o que querem e dizem o que querem. A deficiência pode até gerar algum desconforto, mas não impede a pessoa de ter prazer. Para Maia e Ribeiro (2010, p. 169), "[...] a deficiência pode até comprometer alguma fase da resposta sexual, mas isso não impede a pessoa de ter sexualidade e de vivê-la prazerosamente". Nesse viés, tanto $o$ amor quanto sexo e o desejo têm grande influência das 
concepções impostas pela sociedade de normalidade, e essa aniquila qualquer probabilidade de um relacionamento espontâneo.

Mito 5 - A reprodução para pessoas com deficiência é sempre problemática porque são pessoas estéreis, geram filhos com deficiência ou não têm condições de cuidar deles. Segundo Maia e Ribeiro (2010), há tipos de deficiência que pode reduzir a fertilização, mas essa situação também pode ocorrer com qualquer casal dito "normal", o que não os impede de adotar um filho, se for o caso, mas ainda assim, conforme expresso por Maia e Ribeiro (2010, p.171), "[...] mas a infertilidade não torna nenhum ser humano assexuado e nem impede a possibilidade de manter vínculos afetivos e sexuais prazerosos e satisfatórios".

Para os referidos autores, desmistificar esses mitos significa quebrar preconceitos sobre a sexualidade do deficiente intelectual, como algo errado conforme definido pelos padrões de normalidade. Tais conceitos formam obstáculos para a vida afetiva e sexual plena daqueles que são exprobrados pela deficiência, é superar a discriminação social e sexual imposta pelas culturas vigentes, idealizar nas concepções humanas o ideal de sociedade inclusiva.

Nessa perspectiva, o conceito sexualidade frisa o que é o espírito do presente trabalho: sexualidade é uma necessidade que todas as pessoas têm, independentemente das características individuais. Logo, é uma necessidade também das pessoas com deficiência intelectual, e que precisam ser encontrados mecanismos adequados para lidar com a questão.

\section{SEXUALIDADE E VISÃO DOS PAIS}

O tema sexualidade na deficiência intelectual é algo que costuma ser de interesse apenas da família e profissionais envolvidos na questão. Na concepção dos pais, a grande maioria, vê seus filhos, como uma eterna criança, ao menos no domínio da fantasia, sem modelos de crítica e dos valores que caracterizam como adulto. De acordo com Albuquerque (2011), a negação da sexualidade da pessoa com deficiência intelectual por parte 
dos pais, é compreendida como uma forma de autoproteção, de danos emocionais que uma sociedade injusta possa "[...] causar diante dos perigos do mundo" (p. 111). Embora não seja a forma eficaz de encarar os problemas que corriqueiramente surgem ao serem confrontados na sociedade.

Na perspectiva de Pinheiro (2004), diante do espectro dos pais de figura angelical de seus filhos, cria um sistema de defesa diante das ameaças preconceituosas, instalando um alicerce que leva seus filhos ao mais longe possível das questões relacionadas à sexualidade. Os responsáveis pelos filhos têm medo da exposição quando confrontados com a manipulação de seus órgãos sexuais, masturbação, namoro e gravidez. Nesse viés, Pinheiro (2004, p. 201) que ao desenvolver estudo sobre a temática declara: "[...] Constatou que os pais encaram a sexualidade de seus filhos como mais um problema, e um grande grupo sonegam-lhes informações por temerem que estas estimulem a sexualidade e sejam interpretadas como autorização para que mantenham relação sexual".

Desta forma, evidenciam ter dificuldade os pais e desinformação com questões a respeito da sexualidade humana desenvolvida na educação de seus filhos, levando muitos pais a não quererem que eles recebam orientação sexual, temendo que essas informações possam despertar estímulos sexuais, o que na verdade é um equívoco. No momento que recebem orientação, eles terão oportunidade de aprender a selecionar amigos, constituir e usufruir relações que possam levar a uma experiência sexual satisfatória.

Os pais podem usar a educação sexual a seu favor quando tiverem que lidar com questões como, por exemplo, o uso de contraceptivos. Muitos preferem fazer a esterilização, por temer uma gravidez indesejada, pois consideram seus filhos incapazes de cuidar de seus futuros filhos. Logo, a orientação correta facilita o processo de comunicação familiar, e os responsáveis devem procurar ajuda, caso tenham dificuldades para lidar com questões relacionadas à sexualidade de seus filhos. 


\section{SEXUALIDADE E VISÃO DOS PROFISSIONAIS}

Na visão dos profissionais, a sexualidade é uma das questões que mais tem causado dificuldades, problemas e desafios aos professores no seu trabalho em sala de aula. No papel de transmissão de saberes, cabe ao educador levar conhecimento a seus educando, sejam eles prejudicados neurologicamente ou não. Por se tratar de um tema que no passado era evitado, hoje há uma abertura, embora para muitos ainda seja constrangedor, principalmente quando se trata do deficiente intelectual.

Os problemas ligados à vivência da sexualidade têm origem na falta de informação e na aflição, o que faz com que o indivíduo sinta baixa autoestima, culpa e medo. Os profissionais da educação, pais e pessoas com deficiência, segundo Pinheiro (2004), não estão tendo a preparação adequada para atuarem na área da sexualidade humana e nesse viés ela argumenta:

Os estudos sugerem que tanto pais como profissionais sentem-se despreparados, apresentando atitudes confusas e ambivalentes quanto à sexualidade dos filhos e alunos portadores de deficiência mental. Em decorrência, geralmente não Ihes fornecem educação sexual e quando o fazem fica aquém do necessário. As orientações sexuais, quando fornecidas, são para eliminar comportamentos julgados inadequados, não têm como objetivo o resgate da identidade sexual com privilégios e responsabilidades que implicam a sua vivência, nem tão pouco a possibilidade de oportunizar espaço para interagir, retirar dúvidas e expor seus pensamentos (PINHEIRO, 2004, p. 204).

Um estudo realizado por Gabriel (2013), sobre atitudes de pais e profissionais acerca da sexualidade de pessoas com deficiência intelectual, apontou que existem diferenças significativas entre os dois grupos pesquisados, visto que os profissionais têm atitudes mais liberais, enquanto que os pais são mais conservadores. Os profissionais demonstraram ter necessidades de formação para intervirem de forma adequada nas várias manifestações sexuais das pessoas com deficiência e destacaram que era preciso considerar: o envolvimento da família, as diferenças individuais e a promoção de contextos favoráveis nas instituições para as vivências e experiências sexuais desta população. 
É importante ressaltar que a escassez de literatura torna o processo de educação sexual um desafio, para os três grupos: profissionais, pais e pessoas com deficiência. Pinheiro (2004), em seu artigo expõe que antes de realizar programas de educação sexual primeiro têm que investigar os conhecimentos que este grupo possui, e alavancar pesquisas nas áreas mais contempladas. No programa de educação sexual, Pinheiro (2004, p. 203) ressalta que:

As áreas contempladas são: amizade; namoro e relação sexual; casamento; identificação das partes do corpo; sexo e educação sexual; menstruação; interação sexual; contracepção; gravidez, aborto e nascimento; doenças sexualmente transmissíveis; masturbação; homossexualismo e abuso sexual. Em cada uma dessas áreas são investigados conhecimento, experiência, sentimentos/atitudes e necessidades.

Dessa forma, todos necessitam de informação, orientação, pesquisa, diante do tema sexualidade, como forma de acabar com o preconceito existente em relação à pessoa com deficiência intelectual, para que eles possam ter uma vida sexual satisfatória, levando em conta as suas deficiências, não como impedimento, mas como um aprendizado.

\section{SEXUALIDADE E A ESCOLA}

Esta discussão da temática sexualidade tem circulado nas escolas e na sociedade. Segundo os PCNs (1997), um dos motivos que levaram a inclusão desse tema no currículo foi o crescente avanço de casos de gravidez entre alunos e risco de transmissão do vírus da AIDS e HPV.

A LDB n 9.394/96, em seu Art. $2^{\circ}$ declara que o Estado tem o dever de fornecer ensino para todos e fazer valer esse direito. Dessa forma, os PCNs são entendidos como uma das ferramentas que o Estado possui, porque abordam a sexualidade em relação aos aspectos biológicos, psíquicos, sociais e culturais, e reforça a afirmação federal dizendo que "A educação, é dever da família e do Estado, inspirada nos princípios de liberdade e nos ideais de solidariedade humana, tem por finalidade $\circ$ pleno 
desenvolvimento do educando, seu preparo para o exercício da cidadania e sua qualificação para o trabalho" (BRASIL, 1996, p. 3).

Portanto, no Brasil a orientação ou educação sexual nas escolas é normatizada pelos PCN (BRASIL, 1997). Os PCNs trazem atenção para as relações de gênero e prevenção das doenças sexualmente transmissiveis, como eixos básicos norteadores das propostas pedagógicas dos docentes. A sexualidade restringe nas questões biológicas e psicológicas e sociais. As ações pedagógicas devem abordar o corpo com a vivência do meio (BRASIL, 1997).

Segundo Morales e Batista (2010), as famílias oferecem orientação sexual exercida culturalmente, as escolas apenas complementam essa educação, os valores que os alunos trazem de suas famílias, devem ser respeitados, a escola só vai tomar uma posição se esses valores forem violados de acordo com o que foi estabelecido no Estatuto da Criança e do Adolescente (ECA).

A educação inclusiva como uma nova proposta política colocada em prática no Brasil nos últimos anos, não é uma realidade acessível a diferentes graus de deficiência intelectual, continuando a existir instituições brotadas para o atendimento de uma parte desta clientela.

No momento não se pode ofertar garantia de que, alunos com algum tipo de deficiência que frequentam o ensino regular, terão a educação sexual como sugere os Parâmetros Curriculares Nacionais (Secretaria de Educação Fundamental, 1997), por meio dos temas transversais, que inclui nesta área sugestões para o desenvolvimento.

Para Morales e Batista (2010), cabe à escola o papel de promover informações corretas sobre os conceitos próprios da sexualidade humana, estimular e promover pesquisa a respeito de como as diferentes culturas se relaciona com a sexualidade e explicitar e problematizar mitos e falsas crenças. A escola é um bem que pode e deve ser apropriado por todos, isto inclui os deficientes intelectuais. Para que essa apropriação ocorra, família, sociedade e a própria escola, devem conhecer e vivenciar a realidade de vida desse grupo que vive a margem da sociedade. Logo a necessidade de 
abordagens qualitativas, que venham ao encontro com questionamento como é o tema apresentado neste trabalho.

\section{PROCEDIMENTOS METODOLÓGICOS}

Visando atender aos objetivos propostos, além da pesquisa bibliográfica, foi realizada também uma pesquisa de campo de natureza qualitativa. Lüdke e André (2013), pesquisadoras da área da educação, têm adotado a pesquisa qualitativa em suas metodologias, pois esta tem como fonte principal o ambiente natural, com o contato direto do pesquisador com o ambiente e o objeto estudado.

A coleta de dados foi realizada na Associação de Pais e Amigos dos Excepcionais (APAE) de Naviraí MS, que foi fundada em 1977, conforme Gonçalves, Bezerra e Novais (2018), e continua prestando atendimento às pessoas com deficiência até a atualidade. A APAE tem por incumbência prestar serviços de educação especial às pessoas com deficiência, preferencialmente intelectuais e múltiplas, requerer e articular ações em defesa dos direitos, atenção, orientações e cuidados na prestação de serviços, qualidade de vida a pessoa com deficiência em todos os estágios: crianças, adolescentes, adultos e idosos, buscando assegurar-lhes o pleno exercício da cidadania.

Além de prestar atendimento educacional, a APAE presta serviços em oficinas de: trabalhos manuais, teatro, música, dança, hortaliças e outros. Seu intuito é proporcionar a inclusão social, educacional, profissional, produzir a conscientização das pessoas com deficiência junto à sociedade de forma que eles possam exercer sua cidadania e possibilidade de desenvolvimento de suas potencialidades.

A coleta de dados foi realizada por meio de entrevistas semiestruturadas com 6 (seis) pessoas, sendo 3 (três) profissionais da área e 3 (três) membros da família de pessoas com deficiência intelectual. A intenção em pesquisar profissionais da instituição APAE foi pelo fato de terem experiência em relação ao trabalho desenvolvido com pessoas com deficiência intelectual. A escolha das famílias deve-se ao fato de elas terem 
pessoas com deficiência que estudam na instituição. O critério para a escolha das famílias era ter pessoas adultas com deficiência intelectual, que já passaram pela adolescência, visto que os pais ou responsáveis tiveram a oportunidade de acompanhar as fases anteriores vivenciadas por essas pessoas que frequentam a APAE. Assim, por meio dos Quadros abaixo são evidenciadas as principais características das três profissionais entrevistadas (Quadro 1), bem como de representantes das famílias (Quadro 2), caracterizadas por duas mães e uma irmã. No caso da irmã de 27 anos, ela passou a desempenhar o papel de responsável pelo irmão de 43, após o falecimento da mãe. Vale ressaltar que, as terminologias leve para moderada e moderada, foram citadas pelos entrevistados.

QUADRO 1 - Perfil das Profissionais Entrevistadas

\begin{tabular}{|l|c|l|c|c|}
\hline Identificação & $\begin{array}{l}\text { Idade } \\
\text { (anos) }\end{array}$ & \multicolumn{1}{|c|}{ Formação Profissional } & $\begin{array}{c}\text { Tempo de } \\
\text { Serviço na } \\
\text { APAE }\end{array}$ & Observações \\
\hline Gestora & 55 & $\begin{array}{l}\text { Graduação em } \\
\text { Pedagogia. Cinco cursos } \\
\text { de especialização, } \\
\text { incluindo Psicopedagogia } \\
\text { e Educação Especial. }\end{array}$ & $\begin{array}{l}\text { Já atuou na APAE } \\
\text { como professora } \\
\text { e atualmente } \\
\text { como } \\
\text { coordenadora. }\end{array}$ \\
\hline Professora & 57 & $\begin{array}{l}\text { Graduação em } \\
\text { Pedagogia. } \\
\text { Especialização em Séries } \\
\text { Iniciais do Ensino } \\
\text { Fundamental. }\end{array}$ & 20 anos & - \\
\hline Psicóloga & 27 & $\begin{array}{l}\text { Graduação em Psicologia } \\
\text { Grano }\end{array}$ & \\
\hline
\end{tabular}

Fonte: Gonçalves e Barbosa, 2018.

QUADRO 2 - Perfil das Mães e Irmã Entrevistadas

\begin{tabular}{|l|c|l|l|l|}
\hline Identificação & $\begin{array}{l}\text { Idade } \\
\text { (anos) }\end{array}$ & $\begin{array}{c}\text { Formação } \\
\text { Escolar }\end{array}$ & Profissão & Pessoa Com Deficiência \\
\hline Irmã & 27 & $\begin{array}{l}\text { Superior } \\
\text { incompleto }\end{array}$ & $\begin{array}{l}\text { Irmão de 43 anos e } \\
\text { deficiência moderada }\end{array}$ \\
\hline Mãe 1 & 39 & $\begin{array}{l}\text { Superior } \\
\text { completo }\end{array}$ & $\begin{array}{l}\text { Funcionária } \\
\text { pública }\end{array}$ & $\begin{array}{l}\text { Filho de } 20 \text { anos e } \\
\text { deficiência moderada }\end{array}$ \\
\hline Mãe 2 & 57 & $\begin{array}{l}\text { Fundamental } \\
\text { incompleto }\end{array}$ & Costureira & $\begin{array}{l}\text { Filha de 43 anos e } \\
\text { deficiência leve para } \\
\text { moderada }\end{array}$ \\
\hline
\end{tabular}

Fonte: Gonçalves e Barbosa, 2018. 
Nos componentes da entrevista semiestruturada, foram contempladas discussões como: a sexualidade do sujeito com deficiência intelectual; se há diferença dos demais indivíduos com nenhuma deficiência; se eles são capazes de lidar com seus impulsos sexuais; comportamentos como masturbação, exibição do sexo, namoro, comportamentos inadequados; qual a atitude tomada diante de tais comportamentos, no caso das famílias; como reagem diante de tais questões; a posição das famílias em questões como namoro e casamento, se a família permite o uso de contraceptivos e se é a favor do casamento.

Após o término da coleta de dados, as entrevistas foram transcritas, sistematizadas e analisadas por meio da análise de conteúdo. Para Bardin (2011), a análise de conteúdo refere-se a um método de categorias que possibilita classificar os significados das mensagens em temáticas, também chamada de categorias de análise.

Cabe salientar que todas as participantes foram previamente informadas sobre as finalidades e procedimentos da pesquisa. Para a entrevista com os profissionais, foi feito o agendamento prévio devidamente escolhido por eles, sendo então realizada na própria instituição. Com os responsáveis pelos alunos, o agendamento foi de acordo com o dia e horário escolhido por eles, sendo a coleta de dados realizada em suas próprias casas. As entrevistas foram gravadas e depois transcritas, sistematizadas para então serem analisadas, conforme apresentadas na sequência.

\section{RESULTADOS E DISCUSSÕES DA PESQUISA EMPÍRICA}

Para a organização dos resultados, são apresentados alguns dos principais questionamentos direcionados às pessoas que participaram do presente estudo, com as respostas tanto das profissionais quanto das pessoas responsáveis, para então se fazer a discussão, fundamentada em autores que estudam a temática.

Assim, todas as mulheres que participaram da pesquisa foram indagadas sobre a diferença da sexualidade das pessoas com deficiência 
intelectual, das outras pessoas que não possuem esse tipo de deficiência, sendo que a maioria acredita que não é diferente, conforme foi citado pela Psicóloga: "Eles são indivíduos e ocorrem as etapas normalmente, como acontece com os indivíduos dito como 'normais'." Também a Mãe 2 concordou com essa ideia: "Eu acho que não é diferente não, porque a pessoa especial é um ser humano como qualquer outro. Até bicho bruto tem... Por que não eles?" As respostas dos profissionais e das famílias foram semelhantes, com exceção da Irmã que dizia haver diferenças, sendo assim justificada: "Sim, porque a pessoa com deficiência intelectual, muitas vezes ela não têm noção da sexualidade. Ela pode sentir desejo sexual em qualquer lugar e não saber distinguir se aquele local ela pode... se ali pode ser realizado sua vontade sexual ou não."

As respostas evidenciam que para a maioria a sexualidade é vista como característica comum a todas as pessoas e independente se há alguma deficiência ou não, todos têm direito de usufruir da sua sexualidade. Nesse sentido, Glat (1992, p. 66) comenta: "Pessoas ditas excepcionais não são necessariamente excepcionais em seus impulsos e desejos sexuais. Elas têm necessidades normais, experiências normais e emoções humanas normais". Por outro lado, Maia (2001) afirma que comportamentos sexuais relacionados a pessoas com deficiência são tratados como processos complexos. Assim, muitos pais e profissionais ao serem confrontados com comportamentos sexuais, por mais que tenham recebido orientação sexual, têm dificuldades na tomada de decisão e tem reação que acabam gerando mais desconforto para eles mesmo. Para Ribeiro (2001), pessoas com deficiência são privadas de manifestar seus desejos e impulsos sexuais, por não entenderem a complexidade de tais desejos e faltarem condições de aprendizagem de como ajustar esses desejos e impulsos frente às normas sociais existentes.

No que se refere aos comportamentos sexuais das pessoas com deficiência intelectual, as participantes da pesquisa acreditam que não são todos iguais, que pode variar dependendo da situação ou da pessoa. A Mãe 1 respondeu: 
Não são iguais. Esse comportamento varia, pois pessoas com alto grau de deficiência têm mais dificuldade de entender tais atos e aí ficam se expondo sem restrição alguma, não compreendem as orientações dos pais. É principalmente para esse grupo a indicação de um médico psiquiatra, que poderá receitar medicamentos que ajuda a acalmar essa fase sexual (MÃE 1).

Nesse mesmo viés a Irmã confirma: "Não, porque depende da deficiência intelectual de cada indivíduo, porque cada um vai agir da maneira que o seu organismo pede. Muitas vezes alguns sabem o que é correto e outros não". As respostas indicam que as pessoas com deficiência intelectual são semelhantes às demais pessoas no que se refere ao seu interesse pelo sexo. O que pode ocorrer é que, devido aos comprometimentos neurológicos, eles não sabem muitas vezes distinguir o momento certo de manifestar seus desejos e acabam demonstrando publicamente, gerando reações negativas por parte de uma sociedade preconceituosa.

Nessa mesma sociedade, é permitido a mídia expor sexo explícito em canais de TV aberto, revista exposta em bancas com mulheres mostrando o corpo o chamado nu artístico, e frequentemente depara-se com casais na rua "ditos normais" em cenas sensuais, com comportamentos vistos como inadequados. Mas a sociedade os ignora, o que não seria a mesma situação se fossem pessoas comprometidas neurologicamente. Na opinião de Pinheiro (2004), muitas vezes, pessoas com deficiência intelectual são associadas como seres que não possuem sexualidade.

É interessante notar que Ribeiro (2001) denota que pessoas com deficiência intelectual são capazes de compreender sobre as questões envolvidas nos comportamentos sexuais. Sugere que é necessário que pais e educadores os auxiliem na elaboração de conceitos e formas adequada de comportamentos para manifestar sua sexualidade, levando em conta o nível de desenvolvimento cognitivo de cada indivíduo.

Vale destacar a opinião da Mãe 1, quando faz alusão a medicamentos para casos de pessoas com alto grau de comprometimentos, essa postura vai confrontar com as ideias de Ribeiro (2001), de que a 
exploração e a experimentação sexual são de vital importância para o acrescimento nos aspectos erótico-afetivo. Pinheiro (2004) sintetiza que pessoas com alto grau de comprometimentos intelectual apresentam comportamentos diferentes dos demais, são procedentes da forma como eles vêm sendo abordados e não pela deficiência em si mesmo.

Ao indagar os pais sobre 0 uso de contraceptivos, todos concordaram com o uso. A Mãe 2 fez o seguinte comentário: "Eu aceitaria, nela mesmo eu aplico injeção nela, mesmo que ela não tem alguém, eu me previno, porque eu não sei o que pode acontecer". Em geral, hoje os jovens procuram se precaver de uma gravidez indesejada, na maioria dos casos as famílias orientam seus filhos neste sentido.

No caso de pais com filhos com algum tipo de deficiência não é diferente, eles também tomam os devidos cuidados em relação aos seus filhos, por temerem uma gravidez indesejada. Neste caso os pais levam em consideração a dificuldade dos filhos diante de sua deficiência, pra quem é responsável por essa pessoa pode ser complicado ter que cuidar e educar uma nova criança.

Citando as ideias de Glat (1992), uma das abordagens mais notada por parte de alguns pais, é ver a sexualidade de seus filhos como uma figura angelical e infantilizada. Ao tratar seu filho como anjinho e eterna criança, esse indivíduo vai sempre ter comportamentos infantis, e por estar superprotegido pelos responsáveis, ele vai ter dificuldade de tomar decisões, relacionar em grupos, criar imagens a partir da convivência com grupos da mesma faixa etária.

Ao opinar se consideram adequadas ou não alguns comportamentos de pessoas com deficiência intelectual, como masturbação, exibição do órgão sexual e demonstração de atração pelo outro por meio de palavras e carinhos, todos os entrevistados consideram que esses comportamentos são vistos como adequados, conforme justificado pelas mães:

Serão considerados comportamentos inadequados se não for trabalhado a noção de limites. Esse tipo de comportamento nunca será bem visto se forem praticados a vista de todos, isso tanto por pessoas normais quanto deficientes, pois existe local 
apropriado para tais atos, como seu quarto, por exemplo. Deve ser trabalhada a noção de privacidade desde cedo (MÃE 1).

[...] os normais também fazem e eu não acho nada de anormal. Se ver, faço de conta que não vejo. Ele não sabe onde pode, onde deve, a diferença é só essa. As pessoas "ditas normais" hoje fazem o que vem na teia, imagina a pessoa que é especial? Ele vai fazer onde der vontade [...]. Não é o meu caso, graças a Deus até hoje, mas se acontecer vou saber como lidar (MÃE 2).

Segundo a Mãe 1, comportamentos assim têm que ser trabalhados com todos os filhos desde pequenos, seja comprometido neurologicamente ou não. Para ela existe local e hora apropriada para tudo, enquanto a Mãe 2 considera normal a pessoa "fazer" onde der vontade, até porque, ela diz que os "normais" fazem onde bem entender, mesmo tendo capacidade de escolher local e momento certos.

Sob esse viés a Coordenadora relata "[...] pra eles é tudo normal, beijar... sabe? Eles não têm aquela... aquela coisa que nós temos. Pra eles é normal. Carinho pra eles é normal, puxar o cabelo é normal, é uma forma de carinho pra eles, qualquer manifestação, alegre, triste, chorando...". As respostas evidenciam que esse pudor de anormalidade só existe para quem não tem deficiência intelectual, visto que as pessoas com problemas neurológicos são todas iguais, porém desprovidas de malícias e preconceitos negativos, vivendo à margem da sociedade.

Para Ribeiro (2001), pessoas com deficiência são privadas de manifestar seus desejos e impulsos sexuais, por não entenderem a complexidade de tais desejos e faltarem condições de aprendizagem de como ajustar esses desejos e impulsos frente às normas sociais existentes.

Em seu relato, a Mãe 1 comenta sobre a necessidade de trabalhar a noção de limites e neste sentido Gaglioto (2009, p. 10) salienta: "Desde que sejam orientados de forma que seu nível cognitivo possa assimilar o conhecimento, podem demonstrar seu desejo de uma forma socialmente aceita. O que lhes falta é um processo efetivo de educação e também orientação sexual". Durante o desenvolvimento da pesquisa de campo na APAE, foi observado que os adultos que frequentam desde cedo a instituição, têm comportamentos já ajustados, por terem passado pelo processo de educação sexual. É claro que não segundo os mesmos padrões 
impostos pela sociedade, mas é visível que o trabalho que vem sendo administrado na instituição tem ajudado os alunos a se desenvolverem nos aspectos cognitivos e emocionais.

De acordo com Gaglioto (2009), de fato muitos pais e educadores têm feito o papel de apenas intervir, proibir certas manifestações sexuais. A informação, o conhecimento e o saber sobre a sexualidade ainda é limitado, as informações devem ser elaboradas na afetividade, na ética e nos valores, debater de forma humana e didática, com critérios na formação sexual.

$\mathrm{Na}$ abordagem sobre presenciar cenas de masturbação e atitude tomada por parte dos entrevistados, os profissionais relatam que na APAE é frequente alunos masturbarem em sala, e assim a Professora argumenta: "[...] a forma de lidar, a gente tem que lidar normalmente muitas vezes nem os outros percebem. A gente chega, convida-os... vai ao banheiro um pouquinho, dá uma volta, incentiva-os a sair, distrair um pouco... E assim acaba tudo normal".

Como essa Professora já está na instituição há mais de 20 anos, ela tem experiência com esses alunos e, com jeitinho, chama a atenção para uma atividade que vá distrair a atenção deles para outra situação. Lembrando que o aluno com deficiência intelectual está sujeito às mesmas regras e limitações dentro do contexto escolar. Há, porém, casos mais específicos como o citado pela Gestora sobre um aluno que constantemente se masturba. Ela assim explica:

[...] um exemplo é um aluno que a gente tem, que onde ele sentir o toque, qualquer coisa, seja mão, cadeira, professora... Pra ele o momento de masturbação é o tempo inteiro, e tudo é normal. Quando isso acontece, os outros alunos, embora não tenham conhecimento muito disso, não sabem. Quando o aluno é mais comprometido, tem mais dificuldade, na verdade então o outro também aprende como normal. Aquela coisa de vergonha, pavor... Não têm. É tudo normal (GESTORA).

A reação da Coordenadora é no sentido de interferir no limite de sua competência, formas que irão favorecer a construção de uma sexualidade 
humana, não muito repressiva e nem muito permissiva. Diante de sua reação exclama:

Não é reprimindo de uma vez! Mas é com atenção, cuidado, todo momento que for flagrado isso têm que ser tratado de uma forma mais natural, sem aquela repressão forte. Porque pra eles é assim, no momento que tá ali, você tirou acabou, não existe mais! Agora no momento que ele volta, qualquer atitude que dá prazer pra ele, começa tudo de novo!

É interessante notar segundo os estudos de Gaglioto (2009), o professor deve estar atento a todas as reações que possam surgir, agindo com naturalidade, mas com conhecimento assimilado durante sua docência. Neste sentido ela sugere que grande parte dos problemas relacionados à vivência da sexualidade está na carência de informação e na angústia sentida por esse grupo.

Neste estudo, porém acontece de forma diferente, uma vez que as pessoas entrevistadas na APAE relatam que lá tem um casal com deficiência intelectual e eles têm um filho que nasceu com síndrome de Down, conforme citado pela Psicóloga: "Nós temos aqui na APAE um caso de um aluno que tem os dois, o pai e a mãe são deficientes intelectuais. Porém não é comprovado, só que a gente percebe que são, por lidar com eles há tanto tempo aqui na APAE. Eles tiveram um filho que nasceu com Síndrome de Down". No caso relatado pela Psicóloga, o casal vive junto e o filho estuda na APAE.

Esse relato demonstra que mitos de que pessoas com deficiência são pouco atraentes, indesejáveis e incapazes de manter um relacionamento amoroso e sexual, são vistos como preconceito e é novamente desmistificado na fala da Professora, quando ela relata que:

Sim, nós até ajudamos o relacionamento de um casal de alunos aqui na APAE. A menina foi minha aluna por muito tempo, aí chegou esse rapaz, foi quando percebemos que ela estava interessada. Deram trabalho! Ela já estava com outra professora, foi que eles chegaram a morar junto. Mas eles tiveram dificuldades financeiras, eles recebiam benefício do governo, mas a família na maioria das vezes é que usufrui da renda. O que sobra pra eles é muito pouco. A mãe dela levou o menino para morar com junto na casa, dando todo apoio. Separaram uns cômodos na casa pra eles, puseram um fogãozinho... Mas a família ficava com o salário dele, não queria passar nada pra ajudar. A mãe da menina foi desgastando, 
teve que se separar. Foi por isso, famílias em situação econômica baixa, usam o dinheiro deles pra manter toda a família (PROFESSORA).

Neste caso a união não perdurou por muito tempo, faltou cooperação da família na questão financeira, já que o auxílio que o casal recebia era usado pelos familiares e não pelo casal. É possível perceber pelo depoimento que a deficiência pode apresentar algum tipo de dificuldade, mas não impede o indivíduo de amar e ser amado, são capazes de manter relacionamentos amorosos, além disso, é de vital importância na vida de qualquer humano.

Duas entrevistadas, Irmã e Mãe 1, são a favor do casamento e até mesmo permitiria o casamento, isso no caso que oferece condições favoráveis para a união. Há por exemplo o filho da Mãe 2, ela queria muito que ele tivesse condições de ter um relacionamento, mas devido às condições físicas e neurológicas não é possível. Estando com 20 anos de idade, depende da mãe pra comer, tomar banho... Por meio da entrevista foi possível constatar que essa mãe sempre lutou para que seu filho desfrute a vida da melhor maneira possível. Assim ela relata: "Eu sempre trabalhei para a independência do meu filho, mas infelizmente ele não teve uma evolução necessária para realização de tal ato. Se ele tivesse entendimento para tal escolha eu o apoiaria e o aconselharia a usar os métodos contraceptivos". Nesse relato a mãe apoiaria o uso de contraceptivos, apoio no casamento, mas infelizmente não é possível, devido ao grau de comprometimento neurológico do filho.

Ribeiro (2001) argumenta que estudo tem revelado que se os coeficientes de inteligência (QIs) têm decréscimo, como é ocaso de pessoas com grau de comprometimento neurológico, a maturação sexual também acompanha esse decrescimento. Logo, não são todas as pessoas com algum tipo de deficiência intelectual que vão chegar ao ponto de ter um relacionamento sério que leve ao casamento. Também não são todas as pessoas com deficiência intelectual que irão se interessar pela vida afetivosexual. 
Muitos deficientes podem manifestar a necessidade de outras formas de exercício de sua sexualidade. Alguns podem apenas querer namorar, trocar intimidades, beijarem-se, usufruir do prazer de compartilhar sua vida com uma outra pessoa, que pode ser valorizada pelo aspecto da companhia e da amizade (RIBEIRO, 2001, p. 16).

A sexualidade, como já exposto, pode ser uma palavra que transmite prazer, um afago, gesto de carinho, sensações sentidas desde o ventre da mãe e ao nascer vai perpetuando ao longo da vida por meio dos estímulos provocados ou recebidos de outrem. A busca do prazer se dá de várias formas, em variadas circunstâncias, não se resume apenas no ato sexual (SOUZA, 2008).

A Gestora comentou sobre um fato interessante, que rompe com o mito de que a reprodução para pessoas com deficiência é sempre problemática, por serem estéreis, por gerarem filhos com deficiência ou por não terem condições de cuidar desses filhos. Assim, explica sobre uma pessoa com deficiência que teve uma filha que agora cuida da mãe:

Nós tivemos uma aluna há muito tempo, ela inclusive teve uma filha, hoje a filha que cuida da mãe. É engraçado, bonito de se ver. Nem a família, nem a mãe... Elas não falam como aconteceu a gravidez. Nem a aluna sabe. Essa menina já é adulta, né... Então, engraçado que ela ainda é aluna nossa. Quando ela passa mal, a filha vem aqui acudir a mãe (GESTORA).

Quando a Gestora foi indagada se a criança nasceu com algum tipo de deficiência ela respondeu: "Não, até o momento não percebemos nada de diferente". Esse comentário demonstra que dizer que pessoas com algum tipo de deficiência são estéreis é um mito. De acordo com Maia e Ribeiro (2010), a infertilidade pode ocorrer com qualquer pessoa, há casais ditos normais que têm problemas de fertilização. Logo há tipos de deficiência que podem reduzir a fertilização, mas na fala da Coordenadora, a aluna da APAE teve uma filha que nasceu sem nenhum tipo de deficiência, demonstrando que todos têm direito de gerar um filho, dentro de seus limites, mesmo que tenham algum tipo de deficiência.

A maioria das participantes, ao serem indagadas sobre participação de alguma discussão ou programas que tratam do tema sexual/sexualidade, 
relata que praticamente não há programas neste sentido. A Psicóloga está na instituição há pouco mais de um ano e durante esse tempo não houve eventos para discutir esse assunto. A Coordenadora e a Professora já atuam há mais de 20 anos na APAE e participaram de eventos importantes.

Sim, muitas vezes! Já fui a um congresso em São Luis, que tive essa palestra da
sexualidade. Na época eu ainda estava em sala de aula, trabalhava com crianças
precoces, mas como a gente tem estudo da educação precoce, nós fizemos
questão de participar nessa área. Porque a Professora (entrevistada) ela têm esses
grandes que não têm a sua sexualidade reservada. Nós estamos falando desse
aluno com mais dificuldade. Essa palestra que nós fomos em São Luís do Maranhão,
outra em Belo Horizonte e aqui também já tivemos palestrantes (COORDENADORA).

Sem dúvida é de grande importância programas de intervenção em orientação ou educação sexual para essa população, diante das dificuldades encontradas nessa área. Entretanto, os programas precisam envolver os pais dos alunos, visto que no relato destes, evidenciam que não recebem ajuda nesse sentido. A Irmã assim respondeu: "Não, nunca participei". A Mãe 2, também disse que não, com exceção da Mãe 1, que participou em programas quando morava na capital do Estado de Mato Grosso do Sul.

\begin{abstract}
Morei 7 anos em Campo Grande-MS e na APAE de lá fui convidada a participar de um projeto cujo nome era "Girassol em Movimento" e nesse grupo era trabalhado com as famílias que gostariam de participar. O assunto era "o desenvolvimento sexual do deficiente". Foi um trabalho que durou cerca de 1 ano, onde foi produzido um vídeo das famílias relatando esse assunto e esse vídeo foi escolhido para participar do Congresso Nacional das APAEs. Foi um grupo muito bom, sinto muita saudade dessa turma (MÃE 1).
\end{abstract}

O trabalho realizado na instituição é sem dúvida muito relevante. $\mathrm{E}$ mesmo considerando o fato de os pais não receberem algum tipo de orientação, não desqualifica o trabalho que vem sendo desenvolvido na instituição. Isso pode ter acontecido porque segundo Pinheiro (2004), de um modo geral, os profissionais não estão tendo a preparação adequada para atuarem na área da sexualidade humana e nem sempre é fácil desenvolver atividades educativas que envolvam as famílias.

Assim, entende-se que é importante que haja formação tanto para as famílias quanto para os profissionais que trabalham com pessoas com 
deficiência, para que encarem com maior naturalidade a sexualidade dessas pessoas que já sofrem de diversas formas de exclusão diante da sociedade e nem sempre têm o direito de desfrutar de sua própria sexualidade.

\section{CONSIDERAÇÕES FINAIS}

Este estudo entende a pessoas com deficiência intelectual como pertencentes a um contexto social, com capacidades de se relacionar sexualmente, sujeitos aos mesmos direitos e deveres, sujeitos às mesmas regras, dentro das limitações de cada indivíduo. Todos, com algum tipo de deficiência ou não, têm direito de viver sua sexualidade.

A falta de orientação e educação sexual é que os impedem de entender e desenvolver seus sentimentos e desejos pertinentes em todos os seres humanos o que faz com que o indivíduo sinta baixa autoestima, culpa e medo, e muitas vezes são vistos como um ser assexuado, sem o direito de viver plenamente a sua sexualidade e seu afeto, sendo sua sexualidade carregada de conotações negativas e preconceituosas.

Os mitos e crenças existentes a respeito das pessoas com deficiência intelectual precisam ser desmistificados e tratados de forma natural por toda a sociedade. Educação é a forma ideal para desmistificar tais mitos e conceitos errados que permeiam a sociedade, visa à formação da pessoa, com capacidade de crescer interiormente, viver e escolher sua sexualidade, como cidadão, assim como o faz a educação formal.

No caso da pesquisa realizada com profissionais e responsáveis, por pessoas com deficiência intelectual, alguns mitos não se confirmam, visto que as pessoas com deficiência têm condições de viver a sua vida sentimental e sexual, tendo inclusive capacidade para gerar filhos sem deficiência, que poderão se tornar os seus principais cuidadores.

Também é possível constatar que o trabalho desenvolvido pela instituição APAE é referência no que tange à dedicação dos professores para com os alunos, mas falta a participação dos pais nos debates sobre a questão da sexualidade. Nesse contexto, evidencia-se a necessidade de 
haver iniciativas que incluam capacitar também os pais, porque nas entrevistas com os responsáveis pelos filhos, a maioria respondeu que nunca participaram de discussão ou programa sobre sexualidade.

Com base no estudo realizado, é possível afirmar que, independentemente se a pessoa tem ou não deficiência, a sexualidade é a mais normal das características humanas sentidas por todos e todos têm o direito de usufruí-la. Como ainda existem diversos tabus ou mitos em relação à sexualidade de pessoas com deficiência, e neste estudo que não teve a pretensão de esgotar a temática, por abordar apenas sobre a deficiência intelectual, sugere-se que novos estudos sejam realizados para melhor entender essa problemática. Espera-se que as barreiras sejam rompidas para que a sociedade encare com naturalidade o fato de pessoas com deficiência terem as mesmas necessidades e direitos no que diz respeito à sexualidade humana.

\section{REFERÊNCIAS}

ALBULQUERQUE, P. P. Sexualidade e deficiência intelectual: um curso de capacitação para pais. Psicologia e Argumento. Curitiba, v. 29, n. 64, jan./mar., 2011, p. 109-119.

BARDIN, L. Análise de conteúdo. São Paulo: Edições 70, 2011.

BRASIL. Parâmetros curriculares nacionais: pluralidade cultural, orientação sexual. v. 10. Brasília: MEC/ SEF, 1997.

BRASIL. Estatuto da criança e do adolescente. Lei Federal $n^{\circ} 8.069$, de 13 de junho de 1990. Braślia Distrito Federal.

BRASIL. Lei de Diretrizes e Bases da Educação Nacional n 9394/96. Brasília: Ministério da Educação e Cultura, 1996. Disponível em: <http://www.planalto.gov.br/ccivil_03/leis/L9394.htm>. Acesso em: 12 set. 2018.

DREYER, L. R. O.; MATEUS, M. A. R.; GONÇALVES, J. P. Pessoas com surdez e suas relações com a sexualidade: silenciamentos e descobertas. Textura, Revista de Educação e Letras, v. 20 n. 44, set/dez. 2018. Disponível em: <http://www.periodicos.ulbra.br/index.php/txra/index>. Acesso em: 30 set. 2018. 
FAVERO, C. O que é sexualidade. Infoescola, 2018. Disponível em: <http://www.infoescola.com/sexualidade/o-que-e-sexualidade>. Acesso em: 18 set. 2018.

GABRIEL, C. A. C. Sexualidade da pessoa com deficiência intelectual: atitudes de pais e profissionais, 2013, 94 p. Dissertação (Mestrado em Psicologia). Instituto Universitário Ciências Psicológicas Sociais e da Vida, Lisboa, Portugal, 2013.

\section{GAGLIOTTO, G. M. A Educação Sexual da Criança e a Pedagogia da}

Infância: matrizes institucionais, disposições culturais, potencialidades e perspectivas emancipatórias. 2009. 260 p. Tese (Doutorado em Educação) Faculdade de Educação, Universidade Estadual de Campinas, Campinas, 2009.

GAGLIOTTO, G. M. Faust, T. Santos B. A. O deficiente intelectual e sua sexualidade, um estudo psicanalítico contribuindo para a ação pedagógica. Anais do Congresso Internacional Interdisciplinar em Sociais e humanidade. Niterói RJ: PPGSD-UFF, 03 a 06 de Set., 2012.

GLAT, R. A sexualidade da pessoa com Deficiência Mental. Revista Brasileira de Educação Especial. Marília, v. 1 n. 1 supl. 01, 1992, p. 65-74. Disponível em: <http://www.abpee.net/homepageabpee04_06/artigos_em_pdf/revistal nu merolpdf/rl_art06.pdf>. Acesso em: 12 ago. 2018.

GONÇALVES, J. P.; Bezerra, G. F.; Novais, R. S. O princípio da educação especial em Naviraí/MS: professoras que contam a história. História \& Ensino, Londrina, v. 24, n. 1, p. 229-254, jan./jun. 2018. Disponível em:

<ttp://www.vel.br/revistas/vel/index.php/histensino/article/view/31929/23912 >. Acesso em: 30 set. 2018.

LUDKE, M. A. D. E. MARLI. Pesquisa em educação: abordagens qualitativas. São Paulo. EPU, 2013.

MAIA, B. C. A., RIBEIRO, M. R. P. Desfazendo mitos para minimizar o preconceito sobre a sexualidade de pessoas com deficiência. Revista Brasileira. Ed. Esp., Marília, v.16, n.2, mai./ago., 2010, p.159-176.

MAIA, B. C. A. Reflexões Sobre a Educação da Pessoa com Deficiência. Revista Brasileira. Ed. Esp., Universidade Federal de São Carlos, São Paulo. v. 7, n 1, mai./ago., 2001, p.35-46.

MORALES, S. A. BATISTA, G. C. Compreensão da Sexualidade por Jovens com Diagnóstico Intelectual. Psicologia: teoria e pesquisa. Universidade Estadual de Campinas. v. 26, n. 2, p. 235-244, abr./jun., 2010. 
MUSSKOPF, S. A. Quando sexo, gênero e sexualidade se encontram. Tempo e Presença. ano 3, n. 8, abr., 2008. Disponível em:

$<$ http://www.koinonia.org.br/tpdigital/detalhes.asp? cod_artigo=161\&cod_bo letim=9\&tipo=Artigo $>$. Acesso em: 16 set. 2018.

PINHEIRO, S. N. S. Sexualidade e eficiência Mental: Revisando pesquisas.

Sexualidade e deficiência mental. Psicologia Escolar e Educacional, Pelotas, v. 8, n. 2, p. 199-206, 2004.

REDECE, Rede Brasileira de promoção de informações e disponibilização da contracepção de emergência. O que é Sexualidade. Disponível em: <http:// www.redece.org. >. Acesso em: 16 set. 2018.

RIBEIRO, F. C. H. Sexualidade e os portadores de deficiência mental. Revista Brasileira de Educação Especial, v.7, n.2, 2001.

RIOS, R. D. Mini dicionário escolar da língua portuguesa. São Paulo: Novo Milênio, 2001.

SOUZA, F. K. E. M. O Corpo e a Sexualidade no Contexto Escolar. Caderno Pedagógico. 2008, p. 01 a 83. Disponível em:

<http://www.diaadiaeducacao.pr.gov.br/portals/pde/arquivos/2048-6.pdf>. Acessado em: 16 ago. 2018.

Recebido em: 06 de fevereiro de 2019 Aprovado em: 04 de julho de 2019 